Original Article

\title{
A MORPHOLOGICAL STUDY OF PLACENTA IN CHILDREN WITH AND WITHOUT HYPOSPADIAS
}

\author{
Bindhu $S^{1}$, R K Avadhani $^{2} \&$ Meera Jacob ${ }^{3}$ \\ ${ }^{1}$ Associate Professor, ${ }^{2}$ Professor \& HOD, ${ }^{3}$ Assistant Professor, Department of Anatomy, Yenepoya M edical College, \\ Yenepoya University, M angalore, Karnataka, India. \\ Correspondence : \\ Bindhu S \\ Associate Professor, Department of Anatomy, Yenepoya M edical College, Yenepoya University, Mangalore 575018, Karnataka, India. \\ Mobile : +919945666156 E-mail : nairbindhu@yahoo.com
}

\begin{abstract}
:
Introduction : Hypospadias can be defined as an abnormal urethral orifice under surface of the penis with or without chordee and with or without dorsal hood. At a critical time in sexual differentiation of the male fetus, HCG enters fetal plasma from syncytio trophoblast; acts as an LH surrogate and stimulate replication of testicular Ley dig cells and testosterone synthesis to promote male sexual differentiation. The placental insufficiency may disrupt the supply of nutrients and hcG to the fetus leading to growth retardation and hypospadias.
\end{abstract}

Aim : The aim of this study was to observe and document morphological changes of placenta in children with hypospadias and compare with controls.

Materials \& Methods: The present study was a case control study from July 2008 to July 2011 The data base of the labor registries of the hospital indicated that there were total 3243 male births during this period. All examined for presence / absence of hypospadias by attending pediatrician. Hypospadias was detected in 17 male newborns. Control cases comprised of 68 male newborns without hypospadias of similar gestational age and birth weight collected by cluster sampling.

Result:

Total number of male birth during the study period was 3243 , in that 17 children born with hypospadias. The incidence of hypospadias in our hospital was $0.52 \%$. Gestational age, Birth weight, Placental weight, Placental thickness, Placental volume, volume of infarcts, F.P Ratio, Cord length, were similar in children with hypospadias when compared with controls. CONCLUSION: Fetal factors like gestational age, birth weight, placental weight, Feto-placental ratio were not significantly associated with hypospadias. This study shows no role of placenta in the etiology of hypospadias in children with normal birth weight.

Keywords : Hypospadias, Feto-placental ratio, Placenta.

\section{Introduction:}

Hypospadias, in boys, defined as an association of three anomalies of the penis:(1) an abnormal ventral opening of the urethral meatus that may be located anywhere from the ventral aspect of the glans penis to the perineum, (2) an abnormal ventral curvature of the penis (chordee), and (3) an abnormal distribution of foreskin with a "hood" present

Access this article online Quick Response Code

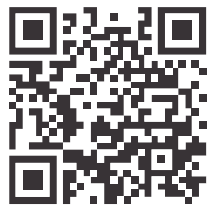
dorsally and deficient foreskin ventrally. ${ }^{1}$ Hypospadias is typically diagnosed at new born physical examination. This is not always the case for boys with milder forms of hypospadias or a non-retractile prepuce or for those with the megameatus intact prepuce(MIP) variant ${ }^{2,3,4}$. These boys may escape diagnosis until the foreskin is fully retracted or circumcision is performed. Although uncommon, simple apparently isolated hypospadias may be the only visible indication of a significant underlying abnormality. The only treatment for this condition is surgery. Thus prevention is imperative. To accomplish this, it is necessary to determine the etiology of hypospadias. The association of growth retardation and hypospadias is well established. Fetal testosterone secretion is under the influence of placental hcG during first 14 weeks of gestation. Chorionic gonadotropin stimulates fetal testicular testosterone secretion that is maximum at approximately the same time that maximal level of HCG is attained. Thus, at a critical time in sexual 
differentiation of the male fetus, HCG enters fetal plasma from syncytio trophoblast; acts as an LH surrogate and stimulate replication of testicular Ley dig cells and testosterone synthesis to promote male sexual differentiation ${ }^{5}$.

The placental insufficiency may disrupt the supply of nutrients and hcG to the fetus leading to growth retardation and hypospadias. To validate this hypothesis, we analyzed all the male infants born at our hospital with hypospadias for fetal growth parameters, and collected placentae for detailed evaluation. And assessed maternal risk factors associated with hypospadias by questionnaire proforma.

\section{Materials \& methods:}

The present study was a case control study from July 2008 to July 2011 .The data base of the labour registries indicated that there were total 3243 male births during this period. All examined for presence / absence of hypospadias by attending pediatrician. Hypospadias was detected in 17 male newborns. Control cases comprised of 68 male newborns without hypospadias of similar gestational age and birth weight collected by cluster sampling.

Once hypospadias was identified, the neonate was examined in detail to identify other anomalies, weight at birth, and gestational age. The placenta was collected and examined for placental weight, thickness, placental volume and cord information. Fetus to placental weight ratio was measured as a reference for placental function and intrauterine fetal growth. The placenta of these controls was also subjected to detailed evaluation and examination.

Data was compiled and analyzed by descriptive analysis; comparison of risk factors was done using student t test. $P$ value $\varangle$.05 was considered as significant.

\section{Result:}

Total number of male birth during the study period was 3243 , in that17 children born with hypospadias. The incidence of hypospadias in our hospital was $0.52 \%$. The characteristics of child at birth are considered as fetal demographic factors associated with hypospadias (Table1).
Characteristics of child at birth--Gestational age, Birth weight, Placental weight, Placental thickness, Placental volume, volume of infarcts, F.P Ratio, Cord length, were similar in children with hypospadias when compared with controls (Table 1).Gestational age was similar in hypospadias (38.64 \pm 0.99 weeks) when compared with controls (38.37+1.14weeks). Birth weight in children with hypospadias was $(2.96 \pm 0.19 \mathrm{~kg})$, when compared with controls $(3.01 \pm 0.17 \mathrm{~kg})$. There was no significant difference in placental weight in children with hypospadias $(462.31 \pm 8.56 \mathrm{gm})$ when compared with controls $(461.92 \pm 8.04 \mathrm{gm})$. Placental thickness was similar in children with hypospadias $(2.08 \pm 0.27 \mathrm{~cm})$ when compared with controls $(2.00 \pm 0.00 \mathrm{~cm})$. There was no significant difference in placental volume in children with hypospadias $(362.65 \pm 14.14 \mathrm{cc})$ when compared with controls $(364.22+17 \cdot 17 \mathrm{cc})$. Feto-placental ratio was not higher in children with hypospadias $(6.53 \pm 0.40)$ when compared to controls $(6.74 \pm 0.42)$. There was no significant difference in length of umbilical cord in children with hypospadias vs controls $(58.31 \pm 2.52 \mathrm{vs} 56.85 \pm 2.91$, P0.18).Number of blood vessels in the umbilical cord were normal in children with hypospadias.

Gestational age was similar in hypospadias (38.64 \pm 0.99 weeks) when compared with controls $(38.37 \pm 1.14$ weeks). Birth weight in children with hypospadias was $(2.96 \pm 0.19 \mathrm{~kg})$, when compared with controls $(3.01 \pm 0.17 \mathrm{~kg})$. There was no significant difference in placental weight in children with hypospadias $(462.31 \pm 8.56 \mathrm{gm})$ when compared with controls (461.92 $\pm 8.04 \mathrm{gm})$. Placental thickness was similar in children with hypospadias $(2.08 \pm 0.27 \mathrm{~cm})$ when compared with controls $(2.00 \pm 0.00 \mathrm{~cm})$. There was no significant difference in placental volume in children with hypospadias $(362.65 \pm 14.14 c c)$ when compared with controls $(364.22+17.17 \mathrm{cc})$. Percentage of infarct in the total volume of placenta was similar in both the groups $(3.45 \pm 0.23$ vs3.48 $\pm 0.30, P-0.81)$. Feto-placental ratio was not higher in children with hypospadias $(6.53 \pm 0.40)$ when compared to controls $(6.74 \pm 0.42)$. There was no significant difference in length of umbilical cord in children with 
hypospadias vs controls $(58.31+2.52$ vs56.85+2.91(P-0.18). Number of blood vessels in the umbilical cord was normal in children with hypospadias.

Table 1: Comparison of fetal demographic factors associated with hypospadias

\begin{tabular}{|l|c|c|c|}
\hline Characteristics & $\begin{array}{c}\text { Hypospadias } \\
\text { (n-17) }\end{array}$ & $\begin{array}{c}\text { Controls } \\
\text { (n-68) }\end{array}$ & P-value \\
\hline Gestational age(week) & $38.64 \pm 0.99$ & $38.37 \pm 1.14$ & 0.96 \\
\hline Birth weight(kg) & $2.96 \pm 0.19$ & $3.01 \pm 0.17$ & 0.11 \\
\hline Placental weight(gm) & $462.31 \pm 8.56$ & $461.92 \pm 8.04$ & 0.90 \\
\hline Placental thickness(cm) & $2.08 \pm 0.27$ & $2.00 \pm 0.00$ & 0.32 \\
\hline Placental volume(cc) & $362.65 \pm 14.14$ & $364.22 \pm 17.77$ & 0.78 \\
\hline Feto-placental ratio & $6.53 \pm 0.40$ & $6.74 \pm 0.42$ & 0.16 \\
\hline Cord length(cm) & $58.31 \pm 2.52$ & $56.85 \pm 2.91$ & 0.18 \\
\hline
\end{tabular}

P-value $\varangle .05$ is considered as significant

\section{Discussion :}

M any authors have suggested that disturbance of placental function early in pregnancy is the key mechanism underlying both preterm birth/low birth weight and the improper closure of the urethra, because the placenta is the main producer of pregnancy hormones in early pregnancy and is thus instrumental in the differentiation and development of the fetal organs $s^{6,7,8}$. This study could not find an association between hypospadias risk and preterm birth ( $<37$ weeks gestation) and/or being small for gestational age $\left(<10^{\text {th }}\right.$ percentile) because in this study all the children born with hypospadias were normal birth weight $(>2.8 \mathrm{~kg})$ and all of them were term birth ( $>39$ weeks). It is well known that in normal, preterm and term infants there is a direct relation between birth weight and weight of placenta ${ }^{9}$. In this study, since all the children born with a normal birth weight, there was no significant association between birth weight and placental weight and all placentae were of normal weight. At term, the placenta is approximately $3 \mathrm{~cm}$ thick and measures $15-25 \mathrm{~cm}$

\section{References :}

1. Paulozzi J, Erickson J D, Jackson R J. Hypospadias trends in two U S surveillance systems.Pediatrics.1997;100(5):831-834.

2. Boisen $K$, Chellakooty M, Schmidt I: Hypospadias in a cohort of 1072 Danish newborn boys: Prevalence and relationship to placental weight, anthropometrical measurements at birth, and reproductive hormone levels at 3 months of age. J Clin Endocrinol Metab 2005; 90(7):4041-4046.

3. Duckett JW, Keating M A.Technical challenge of the megameatus intact prepuce hypospadias variant: the pyramid procedure. J Urol 1989; 141(6):1407-1409.

4. Hatch DA, M aizels M, Zaontz M R. Hypospadias hidden by a complete diameter ${ }^{10}$. Placental thickness is closely related to fetal well-being and may be a key factor in perinatal outcome. In this study, all the placentae were of normal thickness because none of the children in the study group were low birth weight. Ultra sonographic study of placental volume found that, placental volume was directly proportional to the birth weight of the babies ${ }^{11}$. However, there is limited information on the relationship between intrauterine placental volume and birth weight ${ }^{12}$. In this study all the children born with normal birth weight and placentae were in normal weight hence volume of placenta in children with hypospadias was similar with the control on comparison.

The ratio of placental weight to birth weight is described as a marker of fetal growth. The correlation of birth weight and placental size is to be expected as both placental weight and size are known to increase as birth weight increases ${ }^{13}$. In this study the feto-placental ratio in hypospadias children was not found to be increased in comparison with the controls.

\section{Conclusion:}

Several studies have found reduced placental function as underlying etiology for low birth weight and hypospadias. In the present study all the children born with hypospadias were of normal birth weight. Fetal factors like gestational age, birth weight, placental weight, Feto-placental ratio were not significantly associated with hypospadias. This study shows no role of placenta in the etiology of hypospadias in normal birth weight children.

\section{Acknowledgement:}

I thank Dr. R.B. Nerli ,Professor \& HOD of Urology, KLE Hospital, KLE University ,Belgaum, for his valuable advice and guidance to complete this study.

prepuce. Surg Gynecol Obstet 1989; 169(3):233-234

5. Stephens FD, Smith ED, Hutson JM : Embryogenesis of hypospadias. In: Stephens FD, ed. Congenital anomalies of the urinary and genital tracts, Oxford, UK: Isis M edical M edia Ltd.; 1996:80-90

6. Hussain N1, Chaghtai A, Herndon CD, Herson VC, Rosenkrantz TS, McKenna PH.Hypospadias and early gestation growth restriction in infants. Pediatrics 2002; 109(3):473-478.

7. Weidner I S, Moller H, Jensen TK, Skakkebaek NE. Risk factors of cryptorchidism and hypospadias.J Urol.1999;161:1606-1609.

8. Aschim EL, Haugen TB, Tretli S, Daltveit AK, Grotmol T. Risk factors for 
hypospadias in Norwegian boys-association with testicular dysgenesis syndrome? Int J Androl. 2004;27(4):213-221.

9. Thame M, Wilks RJ, M cFarlane-Anderson N, Bennett FI \& Forrester TE. Fetal growth is directly related to maternal anthropometry and placental volume. European Journal of Clinical Nutrition. $2004 ; 58$ : 894-900.

10. Sadler T.W. Langmann' M edical embryology, $9^{\text {th }}$ edition. Baltimore, MD: Lippincott Williams and Wilkins; 2004; p.117-48.

11. Wolf $\mathrm{H}, \mathrm{O}$ osting $\mathrm{H}$, Treffers P E.A longitudinal study of the relationship between placental fetal growth measured by ultrasonography. Am J Obstet.Gynecol. 1989;161: 1140-45.

12. Clappe JH, Rizk KH. Appleby - Wineberg SK, Grass JR. Second trimester placental volume predicts birth weight at term. J Soc Gynecol Investig 1995;2:19-22.

13. Fugimoto, Tomohide Suwa ,Kazuhiko Kabe, Tomoko Adachi, Massao Nakabayashi and Teruke Amamiya. Placental insufficiency in early gestation is associated with hypospadias. J Paediatric Surg 2008:43;358-361. 